\title{
Féeries
}

Études sur le conte merveilleux, XVII $-\mathrm{XIX}{ }^{\mathrm{e}}$ siècle

\section{Contes merveilleux, Perrault, Fénelon, Mailly, Préchac, Choisy et anonymes}

Textes établis, présentés et annotés par Tony Gheeraert, avec un conte anonyme édité par Raymonde Robert, "Bibliothèque des Génies et des Fées, vol. 4 », Paris, Champion, 2005.

\section{Delphine Reguig-Naya}

\section{(2) OpenEdition}

12 Journals

\section{Édition électronique}

URL : http://journals.openedition.org/feeries/443

DOI : $10.4000 /$ feeries.443

ISSN : 1957-7753

\section{Éditeur}

UGA Éditions/Université Grenoble Alpes

\section{Édition imprimée}

Date de publication : 1 octobre 2007

Pagination : 244-246

ISBN : 978-2-84310-101-4

ISSN : $1766-2842$

\section{Référence électronique}

Delphine Reguig-Naya, "Contes merveilleux, Perrault, Fénelon, Mailly, Préchac, Choisy et anonymes », Féeries [En ligne], 4 | 2007, mis en ligne le 18 décembre 2013, consulté le 22 septembre 2020. URL : http://journals.openedition.org/feeries/443 ; DOI : https://doi.org/10.4000/feeries.443

Ce document a été généré automatiquement le 22 septembre 2020.

(c) Féeries 


\section{Contes merveilleux, Perrault, Fénelon, Mailly, Préchac, Choisy et anonymes}

Textes établis, présentés et annotés par Tony Gheeraert, avec un conte anonyme édité par Raymonde Robert, « Bibliothèque des Génies et des Fées, vol. 4 », Paris, Champion, 2005.

\section{Delphine Reguig-Naya}

1 Tony Gheeraert procure ici le quatrième tome de la série « l'âge d'or du conte de fées 1690-1709» rassemblant un corpus de contes d'auteurs exclusivement masculins. Un avant-propos rapide (p.9-10) rattache ce principe de différenciation sexuelle à la pratique générique même du conte, elle-même différentielle : les conteurs masculins, hormis le cas assez particulier de Perrault, se caractérisent par leur discrétion et la modestie de leur production au regard de la prolixité des conteuses. L'hypothèse est celle d'une affinité féminine avec le genre alors que la pratique masculine se caractérise d'abord par sa brièveté. Cette prédilection pour la forme courte s'accompagne d'une culture de l'«instabilité générique", définie comme une tendance à dériver vers d'autres formes comme la fable, voire à dénaturer le caractère féerique des textes. Perrault lui-même illustre ainsi la loi générale de ces textes qui se définissent «avant tout, par l'écart qui les distingue de la poétique féminine » et une instrumentalisation du conte qui ne se satisfait plus du souci de plaire. Le volume se propose donc d'explorer « les marges du conte de fées classique, zones périlleuses où la féerie menace de se renverser en son contraire ». Suivent huit sections de textes dont l'ordre est dicté par la succession chronologique. Les principes d'édition demeurent ceux qui ont été retenus pour l'ensemble de la collection.

2 Chaque section est organisée de manière régulière : elle s'ouvre sur une introduction rassemblant quelques éléments biographiques sur l'auteur, détaillant les problèmes éditoriaux (attribution, datation, fixation du corpus), relatant l'histoire du texte et de ses éditions, et proposant des remarques synthétiques sur la poétique de chaque auteur ou recueil ; elle se poursuit par le texte même, abondamment annoté, qu'il s'agisse 
d'éclairer le lexique, les allusions, les références intertextuelles, d'apporter une variante ou un regard critique pertinent sur le passage. La plupart des sections se clôt sur une série d'annexes : documents témoignant de la réception des contes, versions divergentes de certains contes, textes extérieurs au genre du conte mais soutenant une perspective comparative, pièces paratextuelles ou intertextuelles. À l'issue du volume sont enfin donnés les résumés des contes contenus dans le volume, ainsi que leur notice. Cet appareil se trouve encore complété par une bibliographie et un index des personnages.

3 Par le biais des introductions particulières et parfois longuement développées, chaque auteur fait l'objet d'une synthèse qui aborde les questions habituellement posées par le genre à la critique: celle des sources, de la part respective de l'inspiration "folklorique» ou encore "populaire» et de l'émulation littéraire; celle de l'organisation des instances narratives ; celle de l'imaginaire féerique ; celle du rapport du conte à la morale et à son public, et notamment avec l'univers féminin. Certaines de ces introductions sont particulièrement détaillées. Dans le cas de Perrault, Tony Gheeraert, soulignant le "paradoxe de textes à la fortune immense et pourtant " peut-être aussi les plus énigmatiques de notre histoire littéraire » (p. 13), se propose de « restituer à l'académicien la place qui était la sienne dans la dernière décennie des années 1690 : celle d'un conteur parmi d'autres, et non, comme le laissent croire les éditions isolées de ses œuvres féeriques, celle de l'initiateur, du meilleur, voire du seul auteur de contes de fées en son temps" (p.15). La situation de Perrault dans le quatrième volume de la collection, "au sein de cette catégorie minoritaire que constituent les conteurs masculins » prendrait donc elle-même une valeur critique, soit pour signifier « que, sur le marché des valeurs littéraires, les Histoires ou contes du temps passé sont sur le point d'être détrônés par les contes de $\mathrm{M}^{\mathrm{me}} \mathrm{d}$ 'Aulnoy, de $\mathrm{M}^{\mathrm{me}}$ de Murat ou de $\mathrm{M}^{\text {me }}$ d'Auneuil », soit pour souligner la «spécificité de Perrault, et les raisons de son triomphe ». La caractérisation de la poétique de Perrault conduit Tony Gheeraert à entériner la doxa actuelle qui tend à reconnaître dans ses contes une stratégie du travestissement tendant à « légitimer une esthétique du naturel et de la facilité ancrée dans un décor rustique et sans prétention " et donc un chef-d'œuvre de classicisme (p. 82). Après un retour synthétique sur la fortune des contes depuis le XVIII siècle, Tony Gheeraert revient sur l'effet de relativité produit par le choix éditorial qui fait de Perrault un auteur parmi d'autres dans le recueil : «Perrault est, à coup sûr, un conteur marginal qui utilise le genre tout neuf du conte de fées pour se livrer à des expérimentations narratives sans postérité immédiate et qui constituent de véritables réussites, mais il est loin de représenter l'exception absolue qu'on imagine encore trop souvent » (p. 98).

Succède à Perrault l'analyse de la pratique conteuse de Fénelon qui cultive le «merveilleux paradoxal»(p.361). Le précepteur du duc de Bourgogne conçoit des « contes à l'envers où sont moqués la plupart des codes traditionnels du genre » et où le projet éthique oriente les choix poétiques propres à la fable. La parodie du conte atteint l'« l'idéologie galante et mondaine à laquelle, chez les conteuses, il sert le plus souvent de véhicule » (p. 366) et équivaut de fait à une " entreprise de récupération du conte de fées » (p. 369-370) puisque Fénelon «travaille à substituer au cynisme des contes de salons une éthique évangélique fondée sur la simplicité, le renoncement et la lutte contre l'amour-propre ». Cette moralisation, cette christianisation des contes de fées n'empêchent pourtant pas que ces textes restent « de vrais contes, caractérisés par la 
peinture de personnages pittoresques, par la vivacité de la narration et par un sens de l'humour qui les empêchent de sombrer dans un dogmatisme pontifiant » (p. 377).

5 À l'opposé du cas de Fénelon, Louis de Mailly érige une féerie aristocratique, euphémisée et élitiste « en paradigme d'une civilité mondaine et féminine, et assigne ainsi de hautes ambitions littéraires au conte de fées qui devient sous sa plume l'instrument du progrès des mœurs et le miroir de la promotion des femmes » (p. 458). Le conte exalte la culture de cour, célèbre la femme sous les traits de la fée comme " allégorie de la mondaine », « image idéalisée de la lectrice » (p. 481). Mailly parachève ainsi « le processus d'aristocratisation caractéristique du conte littéraire à la fin du XVII ${ }^{\mathrm{e}}$ siècle" (p. 498). Les contes à visée épidictique de Jean de Préchac ne sont en revanche plus contes que par leur construction formelle, les techniques, motifs qu'ils mobilisent. Ces textes qui «relèvent de l'histoire officielle ou de la rhétorique d'apparat » (p. 666) fournissent le prétexte à une allégorie servant l'éloge royal. Autre exemple de détournement du genre, la "féerie tragique " du "Portrait qui parle» orchestre un « anti-conte surprenant et déceptif» (p. 769), pathétique et spectaculaire qui « tient davantage de la poétique de la tragédie lyrique que de celle du conte de fées folklorique ou littéraire ». Le panorama s'achève sur l'Histoire de la princesse Aimonette de l'abbé de Choisy qui tire ses sources de la littérature médiévale réécrite pour plier la chevalerie aux mœurs galantes du nouveau temps: "c'est bien la supériorité de la culture moderne sur la sauvagerie moyenâgeuse que célèbre Choisy lorsqu'il acclimate à l'usage des mondains un classique de la Bibliothèque bleue » (p. 850).

6 Dénaturation, dérive, instabilité, marges de la pratique conteuse : le volume répond ainsi rigoureusement au programme fixé par l'avant-propos et s'organise pour confirmer en effet l'hypothèse d'une spécificité poétique du conte au masculin à la charnière des XVII ${ }^{\mathrm{e}}$ et XVIII ${ }^{\mathrm{e}}$ siècles. 